\title{
PRODUÇÕES ACADÊMICAS SOBRE "ACESSIBILIDADE" NO PORTAL C@THEDRA ${ }^{1}$
}

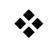 \\ Ana Paula Silva Cantarelli Branco \\ Universidade Estadual Paulista - UNESP/Bauru - Brasil \\ Lucia Pereira Leite \\ Universidade Estadual Paulista - UNESP/Bauru - Brasil \\ Sandra Eli Sartoreto de Oliveira Martins \\ Universidade Estadual Paulista - UNESP/Marília - Brasil
}

\begin{abstract}
Resumo
A eliminação de barreiras de acessibilidade, que impedem e/ou dificultam o acesso à Educação Superior, ganha destaque na atualidade. Esta pesquisa objetivou retratar o conceito "acessibilidade" nas produções científicas brasileiras dos últimos dez anos. Foi realizada uma varredura no portal da C @ thedra, sítio eletrônico da UNESP, o qual disponibiliza resultados de estudos de Mestrado e/ou Doutorado apresentados nos programas de Pós-Graduação da instituição. O levantamento permitiu identificar 66 materiais, sendo 22 teses e 44 dissertações. Do montante dos materiais, 38 foram selecionados para análise, sendo 10 teses e 28 dissertações. Os resultados indicam que as produções científicas versaram sobre acessibilidade arquitetônica, metodológica, comunicacional, programática, seguida de poucos trabalhos que fizeram referência à acessibilidade na perspectiva atitudinal e/ou instrumental para abordar o tema deficiência. Embora tais achados ainda sejam pouco expressivos, diante do total de produções acadêmicas disponíveis na base eletrônica, isso mostra que a temática vem ganhando expressão junto à comunidade científica.
\end{abstract}

Palavras-chave: Acessibilidade. Ensino Superior. Portais eletrônicos.

\section{Acessibilidade: uma breve revisão do conceito}

Sabe-se que o conceito de acessibilidade surgiu nos Estados Unidos, no período posterior à guerra do Vietnã, momento em que os jovens soldados regressavam para suas

\footnotetext{
${ }^{1} \mathrm{O}$ C@ thedra é um portal eletrônico da Universidade Estadual Paulista - UNESP, que disponibiliza resultados de estudos de Mestrado e/ou Doutorado apresentados nos programas de Pós-Graduação da instituição. Disponível em: http://www.athena.biblioteca.unesp.br/F/?func=find-b-0\&local_base=BDTD. Acesso em: dezembro de 2014.
} 
casas mutilados, ou com alguma deficiência, devido aos confrontos ocasionados pela guerra. Nessa época, havia a preocupação em garantir um atendimento de acordo com as necessidades apresentadas pelos soldados, criando-se então o Centro de Vida Independente $(\mathrm{CVI})$, caracterizado como uma organização não governamental que objetivava a reinserção social e o desenvolvimento de uma vida autônoma destes, em sociedade (CARDOSO, 1996).

Em função de acontecimentos semelhantes, pessoas com deficiência reivindicavam seus direitos para o exercício de uma vida ativa e produtiva, em sociedade. A esse respeito, Cardoso (1996) lembra que qualquer indivíduo pode ficar impossibilitado de desenvolver suas funções cotidianas, em algum momento de sua vida, de modo temporário ou permanente. Tal comprometimento pode decorrer de incapacidade e/ou déficit no funcionamento biológico, emocional e/ou cultural no desenvolvimento dos sujeitos, podendo ocasionar perdas irreparáveis para uma vida social autônoma (CARDOSO, 1996; MICHELS, 2000).

A "acessibilidade" foi concebida, por conseguinte, como pressuposto que considera o direito de todos alcançarem na sociedade uma vida independente e autônoma. Todavia, a literatura aponta outros modos de definir acessibilidade, tal como o disposto no Decreto Federal 5.296/2004, em seu artigo $8^{\circ}$, inciso I, que estabelece:

I - acessibilidade: condição para utilização, com segurança e autonomia, total ou assistida, dos espaços, mobiliários e equipamentos urbanos, das edificações, dos serviços de transporte e dos dispositivos, sistemas e meios de comunicação e informação, por pessoa portadora de deficiência ou com mobilidade reduzida. (BRASIL, 2004).

Essa definição cita de modo abrangente alguns objetos aos quais se aplicam os conceitos de acessibilidade - incluem-se desde os ligados às edificações até os meios de comunicação. Destaca também a necessidade de as pessoas “[...] portadoras de deficiência ou com mobilidade reduzida" ${ }^{2}$ utilizarem com segurança e autonomia os objetos produzidos pela humanidade, sem restrições de uso.

Nessa mesma direção, a Nota Técnica 9050/2004 (ABNT, 2004) define, em seu item 3.1, que a Acessibilidade por ser entendida como a "[p]ossibilidade e condição de alcance, percepção e entendimento para a utilização com segurança e autonomia de edificações, espaço, mobiliário, equipamento urbano e elementos”. Tal definição ressalta a importância dos aspectos relacionados à estrutura física, ao empregar o termo.

\footnotetext{
${ }^{2}$ Embora o termo deficiência seja empregado de diferentes formas, ao se remeter à pessoa que se encontra nessa condição, como portadora, pessoa com, deficiente, entre outros, neste texto, será utilizada a expressão pessoa com deficiência.
} 
Três anos mais tarde, preocupada em possibilitar autonomia às pessoas com deficiência, a Convenção Internacional sobre os Direitos das Pessoas com Deficiência, adotada pela ONU, em 30 de março de 2007, em Nova York, enfoca a questão. Esta foi ratificada no Brasil pelo Decreto Federal 6.949, de 25 de agosto de 2009, o qual estabelece, em seu artigo $9^{\circ}$, item 1: “[...] os Estados Partes deverão tomar as medidas apropriadas para assegurar-lhes o acesso, em igualdade de oportunidades com as demais pessoas, ao meio físico, ao transporte, à informação e comunicação, inclusive aos sistemas e tecnologias da informação e comunicação". Essa definição permite ressaltar alguns pontos importantes da vida independente, valorizando a participação plena e o acesso das pessoas com deficiência às oportunidades iguais aos demais membros da sociedade.

Nessa perspectiva, a acessibilidade significa mais do que a participação em atividades e deve ser considerada como um processo de transformação do ambiente, da organização físico-espacial, do atendimento, da administração, do atendimento, das atitudes e/ou do comportamento humano (MANZINI, 2013).

Retomando os dispositivos da Convenção Internacional sobre os Direitos das Pessoas com Deficiência, percebe-se uma preocupação na acessibilidade comunicacional, pois indica que a esfera governamental deve promover o acesso de pessoas com deficiência aos novos sistemas e as tecnologias da informação e comunicação, inclusive aos equipamentos e sistemas virtuais de navegação na internet.

Nesse contexto, a acessibilidade é concebida como a possibilidade e a condição de alcance, percepção, entendimento e interação para a utilização, em igualdade de oportunidades, com segurança e autonomia, em sítios e serviços disponíveis na web, por qualquer indivíduo, em quaisquer circunstâncias, independentemente de sua capacidade motora, visual, auditiva, intelectual, cultural ou social, ou seja, “[...] tornar todos os serviços, assuntos e publicações tão fáceis de serem utilizados por todas as pessoas, que até esqueceremos que há diferenças" (BRASIL, 2013, p. 21).

A descrição de acessibilidade mencionada na Cartilha de Acessibilidade para Web fascículo I (BRASIL, 2013), ampara-se nos fundamentos teóricos do Desenho Universal, em que o desenvolvimento de produtos e ambientes leva em conta todas as diferenças pessoais, sem a necessidade de adaptação. A ideia principal contida no Desenho Universal se constitui a partir da visão de mundo projetada para atender da melhor forma possível a todas as pessoas, ao invés de exigir dessas um grande esforço de adaptação. Esse documento traz exemplos de locais e recursos consoantes aos princípios do conceito de Desenho Universal, como ambientes que possuem rampas de acesso, banheiros, bebedores, fraldários, pisos podotáteis, 
elevadores com áudio e painéis em Braille, filmes com audiodescrição, legendas e tradução para LIBRAS - Língua Brasileira de Sinais, entre outros, que estejam adequados às diferentes necessidades dos indivíduos. Trabalhar dentro dessa perspectiva implica a promoção de ações capazes de favorecer um contexto social inclusivo, garantido a participação de todas as pessoas nas diferentes esferas: saúde, educação, trabalho, lazer etc.

Para os propósitos deste texto, o termo acessibilidade será

[...] concebido como a possibilidade e condição de alcance, percepção e entendimento para a utilização, em igualdade de oportunidades, com segurança e autonomia, do meio físico, do transporte, da informação e da comunicação, inclusive dos sistemas e tecnologias de informação e comunicação, bem como de outros serviços e instalações. (BRASIL, 2013).

Diante da importância do assunto tratado nas considerações feitas até este ponto, a fim de subsidiar este texto, decidimos revisitar as produções bibliográficas observando o emprego da temática "acessibilidade" nas pesquisas no portal C@ thedra, sítio eletrônico da Universidade Estadual Paulista (UNESP), o qual disponibiliza resultados de estudos de mestrado e/ou doutorado apresentados nos programas de Pós-Graduação da instituição. Nessa direção, pesquisou-se o conceito de acessibilidade a partir da ferramenta de busca nos arquivos das produções acadêmicas (teses e dissertações), com a intenção de analisar quais materiais conceituaram "acessibilidade", assim como observar de que maneira a comunidade científica tem abordado a temática em discussão.

Os trabalhos foram analisados com o objetivo de verificar de que forma tratam o conceito de acessibilidade e como este tem sido empregado, para problematizar a superação de barreiras em diferentes dimensões: arquitetônica urbanística - concernente às vias e espaços de uso público; arquitetônica de edificações - existente no interior dos edifícios e prédios, sejam eles públicos, sejam particulares; comunicação - qualquer entrave ou obstáculo que dificulte ou impossibilite a expressão ou o recebimento de uma mensagem, por intermédio dos meios ou sistemas de comunicação; curriculares - são as encontradas no currículo escolar (organização, objetivos, conteúdos, avaliação, procedimentos didáticos, atividades, temporalidades); atitudinais - ocasionadas pelas atitudes das pessoas frente às deficiências e diferenças, como consequência da desinformação e do preconceito (BRASIL, 2000).

Pelo exame do material coletado é possível observar, portanto, que a temática "acessibilidade" se torna usual e recorrente, quando se referencia à pessoa com deficiência; por isso, destacam-se as pesquisas de cunho bibliográfico que têm como função mapear a 
produção acadêmica em diversas áreas do conhecimento. Na verdade, como assinala Ferreira (2002), as investigações realizadas na última década podem se configurar como o estado da arte ou o estado do conhecimento sobre um determinado assunto.

\section{Percurso metodológico}

A proposta desta pesquisa foi investigar, no portal da C@ thedra, uma biblioteca digital de teses e dissertações defendidas na UNESP, trabalhos acadêmicos dessa natureza que tematizassem, de algum modo, a "acessibilidade". Por conseguinte, realizou-se uma busca nesse portal, especificamente em busca simples e avançada, pelo descritor "acessibilidade". No campo para busca, selecionou-se o índice geral de palavras, não sendo incluídas palavras adjacentes; em relação à base para busca, elegeu-se a biblioteca digital de teses e dissertações. Ressaltamos que não foram selecionados os idiomas, os formatos, nem mesmo os anos de publicações.

A busca resultou em 66 materiais localizados no portal da C@ thedra, sendo 22 teses e 44 dissertações. Destas, nove teses e 14 dissertações foram excluídas da análise, por não apresentarem o conceito de acessibilidade ou por deixarem de se relacionar com as temáticas "deficiência" e/ou "mobilidade reduzida". É válido mencionar que outras três teses e duas dissertações também foram excluídas, porque não estavam disponíveis para download no Portal C@thedra, não possibilitando, assim, fazer a leitura do material. Desse modo, a amostra de análise constituiu-se de 10 teses e 28 dissertações.

No que tange à mensuração dos dados, construiu-se um instrumento de sistematização dos resultados bibliográficos, dividindo-se a análise em teses e dissertações, conforme os seguintes itens: a) quantidade de estudos por curso de Pós-Graduação; b) locais que cursaram a Pós-Graduação; c) cursos de Pós-Graduação realizados; d) ano de conclusão. Além disso, foram identificados outros fatores, como: quantidade de teses e dissertações; nome do programa; área do conhecimento humano, de acordo com a Tabela das Áreas do Conhecimento disponibilizada pelo Conselho Nacional de Desenvolvimento Científico e Tecnológico $(\mathrm{CNPq})$; área de concentração; linha de pesquisa e conceitos de acessibilidade abordados em cada estudo. 


\title{
Resultados
}

\author{
Análise das Teses
}

Por meio dessa análise, percebeu-se que os estudos foram concluídos no intervalo de 2005 a 2012, sendo que se encontrou uma predominância de estudos de Doutorado nos programas de Pós-Graduação em Geografia, com um total de seis trabalhos. Outros quatro estudos foram localizados em Programas distintos: um no Programa de Educação, um em Educação para a Ciência, um em Ciências da Informação e um em Engenharia Mecânica.

Para a análise dos estudos, utilizaram-se as dimensões de acessibilidade descritas por Sassaki, (2003), que emprega seis delas para descrever as condições de acessibilidade: a) arquitetônica - desobstrução de barreiras ambientais; b) atitudinal - prevenção e eliminação de preconceitos, estigmas, estereótipos, discriminação; c) comunicacional - adequação de códigos e sinais às necessidades especiais; d) metodológica - adequação de técnicas, teorias, abordagens, métodos; e) instrumental - adaptação de materiais, aparelhos, utensílios, tecnologias assistivas; e f) programática - eliminação de barreiras invisíveis existentes nas políticas, normas, portarias, leis e outros instrumentos afins.

Inicialmente, serão apresentados os achados das teses, seguidas das dissertações encontradas.

Quadro 1- Teses encontradas na base de dados C@thedra, conforme área geral e específica do conhecimento relacionadas ao tema da pesquisa, definições sobre o conceitos e tipos de acessibilidades abordadas pela temática de cada trabalho.

\begin{tabular}{|c|c|c|c|c|c|c|c|c|c|c|}
\hline $\begin{array}{l}\text { Quan } \\
\text { tidad }\end{array}$ & $\begin{array}{c}\text { Nome dos } \\
\text { Programas de }\end{array}$ & Área do & Área de & \multirow{2}{*}{$\begin{array}{l}\text { Linha de } \\
\text { Pesquisa }\end{array}$} & \multicolumn{6}{|c|}{ Formas de Acessibilidade* } \\
\hline & & & & & AA & AT & $\mathrm{AC}$ & $\mathrm{AM}$ & AI & $\mathrm{AP}$ \\
\hline 01 & $\begin{array}{c}\text { PPG - } \\
\text { Educação } \\
\text { UNESP, } \\
\text { Marília }\end{array}$ & $\begin{array}{l}\text { Ciências } \\
\text { Humanas }\end{array}$ & $\begin{array}{c}\text { Sem área de } \\
\text { concentração** }\end{array}$ & $\begin{array}{l}\text { Educação } \\
\text { Especial }\end{array}$ & & & & & & \\
\hline \multirow[b]{2}{*}{02} & $\begin{array}{c}\text { PPG - } \\
\text { Geografia da } \\
\text { UNESP, }\end{array}$ & \multirow[t]{2}{*}{$\begin{array}{l}\text { Ciências } \\
\text { humanas }\end{array}$} & \multirow[t]{2}{*}{$\begin{array}{l}\text { Organização do } \\
\text { Espaço }\end{array}$} & \multirow{2}{*}{$\begin{array}{c}\text { Dinâmicas, } \\
\text { Processos e } \\
\text { Desenvolviment } \\
\text { o Urbano e } \\
\text { Regional }\end{array}$} & & & & & & \\
\hline & Rio Claro & & & & & & & & & \\
\hline \multirow{4}{*}{04} & PPG- & \multirow{4}{*}{$\begin{array}{l}\text { Ciências } \\
\text { Humanas }\end{array}$} & \multirow{4}{*}{$\begin{array}{c}\text { Produção do } \\
\text { Espaço } \\
\text { Geográfico }\end{array}$} & \multirow{4}{*}{$\begin{array}{l}\text { Produção do } \\
\text { Espaço Urbano }\end{array}$} & & & & & & \\
\hline & $\begin{array}{l}\text { Geografia } \\
\text { UNESP, }\end{array}$ & & & & & & & & & \\
\hline & $\begin{array}{l}\text { Presidente } \\
\text { Prudente }\end{array}$ & & & & & & & & & \\
\hline & & & & & & & & & & \\
\hline
\end{tabular}




\begin{tabular}{|c|c|c|c|c|c|c|c|c|c|c|}
\hline 01 & $\begin{array}{c}\text { PPG - } \\
\text { Engenharia } \\
\text { Mecânica, } \\
\text { UNESP, } \\
\text { Guaratinguetá }\end{array}$ & $\begin{array}{c}\text { Ciências } \\
\text { Exatas }\end{array}$ & Projetos & $\begin{array}{l}\text { Engenharia } \\
\text { Semiológica }\end{array}$ & & & & & & \\
\hline 01 & $\begin{array}{l}\text { PPG - Ciência } \\
\text { da Informação } \\
\text { da UNESP, } \\
\text { Marília }\end{array}$ & $\begin{array}{l}\text { Ciência da } \\
\text { Computação }\end{array}$ & $\begin{array}{l}\text { Informação, } \\
\text { tecnologia e } \\
\text { conhecimento }\end{array}$ & $\begin{array}{l}\text { Informação e } \\
\text { tecnologia }\end{array}$ & & & & & & \\
\hline 01 & $\begin{array}{c}\text { PPG - } \\
\text { Educação para } \\
\text { Ciências da } \\
\text { UNESP, } \\
\text { Bauru. }\end{array}$ & $\begin{array}{l}\text { Ciências } \\
\text { Humanas }\end{array}$ & $\begin{array}{l}\text { Ensino de } \\
\text { Ciências }\end{array}$ & $\begin{array}{c}\text { Fundamentos e } \\
\text { modelos } \\
\text { psicopedagógic } \\
\text { os no Ensino de } \\
\text { Ciências e } \\
\text { Matemática }\end{array}$ & & & & & & \\
\hline 10 & & & & & 09 & 01 & $\mathbf{0 2}$ & $\mathbf{0 3}$ & 02 & 01 \\
\hline
\end{tabular}

Fonte: Elaborada pelos autores.

*AA= acessibilidade arquitetônica (física); $\mathrm{AT}=$ acessibilidade atitudinal; $\mathrm{AC}=$ acessibilidade comunicacional; $\mathrm{AM}=$ acessibilidade metodológica; $\mathrm{AI}=$ acessibilidade instrumental; $\mathrm{AP}=$ acessibilidade programática.

**= o Programa sofreu várias alterações e aperfeiçoamentos e, na última modificação, ocorrida em 2012, foram extintas as Áreas de Concentração, permanecendo apenas cinco linhas de pesquisa.

***= As áreas do conhecimento humano foram extraídas da classificação das áreas de conhecimento do CNPq.

Observou-se uma predominância de seis estudos, os quais conceituaram:

a) Apenas Acessibilidade Arquitetônica - encontraram-se, neste caso, três pesquisas na área do conhecimento Ciências Humanas, área de concentração Produção do Espaço Geográfico, linha de pesquisa Produção do espaço urbano. Uma delas procurou discutir acessibilidade como modo de apropriação do espaço público, com o olhar especial para as diferentes formas de acesso, as quais interferem diretamente nas condições de uso e ocupação dos diferentes lugares da cidade, referindo-se estritamente ao espaço físico. Já a segunda considerou a composição da rede urbana regional e as relações interurbanas previstas para o período da economia cafeeira, demonstrando que o acesso à rede urbana dependia não só da acessibilidade física, mas também da acessibilidade social. Por fim, a terceiro estudo examinou os múltiplos espaços na configuração urbana da capital maranhense, tomando como aporte o ponto de vista do cadeirante e como eles têm se apropriado desses espaços. Em acréscimo, têm-se dois estudos na área do conhecimento Ciências Humanas, área de concentração Organização do Espaço, linha de pesquisa Dinâmicas, processos $e$ desenvolvimento urbano. O primeiro elaborou uma teoria da acessibilidade espacial e aplicou um modelo de transporte público para a região, visando a melhorar o atendimento oferecido à população. O segundo se voltou para se compreender a estruturação urbana nas cidades capitalistas e do modo como esta interfere no cotidiano dos citadinos, à medida que estes necessitam locomover-se constantemente para realizar as mais diversas funções e atividades. 
Assim, procurou compreender a situação espacial de cada um, como pode facilitar ou dificultar esses deslocamentos intraurbanos, almejando entender como essas manifestações se apresentam nessa cidade e interferem na vida dos citadinos, no que diz respeito ao exercício do direito à cidade.

E por fim, existe mais um estudo, na área do conhecimento Ciências Humanas, sem área de concentração definida pelo programa, linha de pesquisa Educação Especial, foi localizada uma tese que objetivou, por meio da realização de três estudos, examinar as condições de acessibilidade e a satisfação dos alunos com deficiência em sete faculdades de uma Instituição de Ensino Superior do Estado de São Paulo - além de ter elaborado um protocolo para avaliar a acessibilidade no ensino superior, em relação a rotas ou caminhos dessas faculdades.

b) Acessibilidade atitudinal, comunicacional, metodológica, instrumental $e$ programática - foram localizadas duas pesquisas que conceituaram todas as dimensões de acessibilidade. uma delas enveredou pela área do conhecimento Ciências Humanas, área de concentração Ensino de Ciências, linha de pesquisa Fundamentos e modelos psicopedagógicos no ensino de Ciências e Matemáticas, a qual possibilitou a visualização de uma interface cérebro-computador (ICC), a qual foi pesquisada de forma que se pudesse tornar um recurso assistivo, a fim de facilitar o processo de conceituação de pessoas com deficiência visual e física, em aulas de física.

O outro, na área do conhecimento Ciências exatas, área de concentração Projetos, linha de pesquisa Engenharia Semiótica, teve em vista o aumento de longevidade e a preocupação com a acessibilidade que visa à autonomia e à mobilidade humana.

Levantou-se ainda outra pesquisa, na área do conhecimento Ciência da Computação, área de concentração Informação, tecnologia e conhecimento, linha de pesquisa Informação e tecnologia, referente à acessibilidade metodológica, em que se destacou a natureza atual da World Wide Web (Web), objetivando a participação colaborativa dos usuários em diversos ambientes informacionais digitais, conduzindo ao desenvolvimento de diretrizes que enfocam a arquitetura da informação digital inclusiva para diferentes públicos, nas mais diversas ambiências informacionais. Identificaram-se necessidades e preferências individuais do usuário no uso de recursos comunicacionais para a obtenção da informação, a propósito de "acessibilidade digital", implementada por meio da harmonia bem-sucedida entre a informação e comunicação com relação às necessidades e preferências individuais de um usuário, permitindo que este interaja e perceba o conteúdo intelectual da informação. 
Considera-se que, apesar de o autor ter trabalhado com o conceito de acessibilidade digital, o estudo foi categorizado e incluído nos preceitos conceituais de acessibilidade comunicacional, nos termos de Sassaki (2003).

E, por último, referenciou-se uma pesquisa na área do conhecimento Ciências Humanas, área de concentração Produção do Espaço Geográfico, linha de pesquisa Produção do espaço urbano. Essa investigação, na área da Produção do Espaço, enfatizou que a acessibilidade não é somente física, mas também "simbólica", pois a questão do acesso à cidade está diretamente ligada à demarcação dos diferentes territórios urbanos, contrapondose a uma dimensão simbólica e abstrata, em função de uma concretude física dos espaços urbanos. Nesse sentido, ao se examinar a definição de "acessibilidade" proposta por Sassaki (2003), notou-se que ela não concerne a algo disponível ou possível a todo cidadão, porque está limitada e controlada tanto concreta quanto simbolicamente. Portanto, levou-se em conta que o aparato simbólico conceituado nessa tese está diretamente associado à acessibilidade atitudinal (relacionada ao modo como as pessoas imaginam os próprios espaços), algo que pode ser diferente do real.

\section{Análise das dissertações}

Ao se analisar as dissertações, foram localizadas 28 produções de mestrado que, em alguma medida, discutiram a temática relacionada às dimensões de acessibilidade retratadas neste estudo.

Quadro 2- Dissertações encontradas na base de dados C@thedra, conforme área geral e específica do conhecimento relacionadas ou não ao tema da pesquisa, definições sobre o conceitos e tipos de acessibilidades.

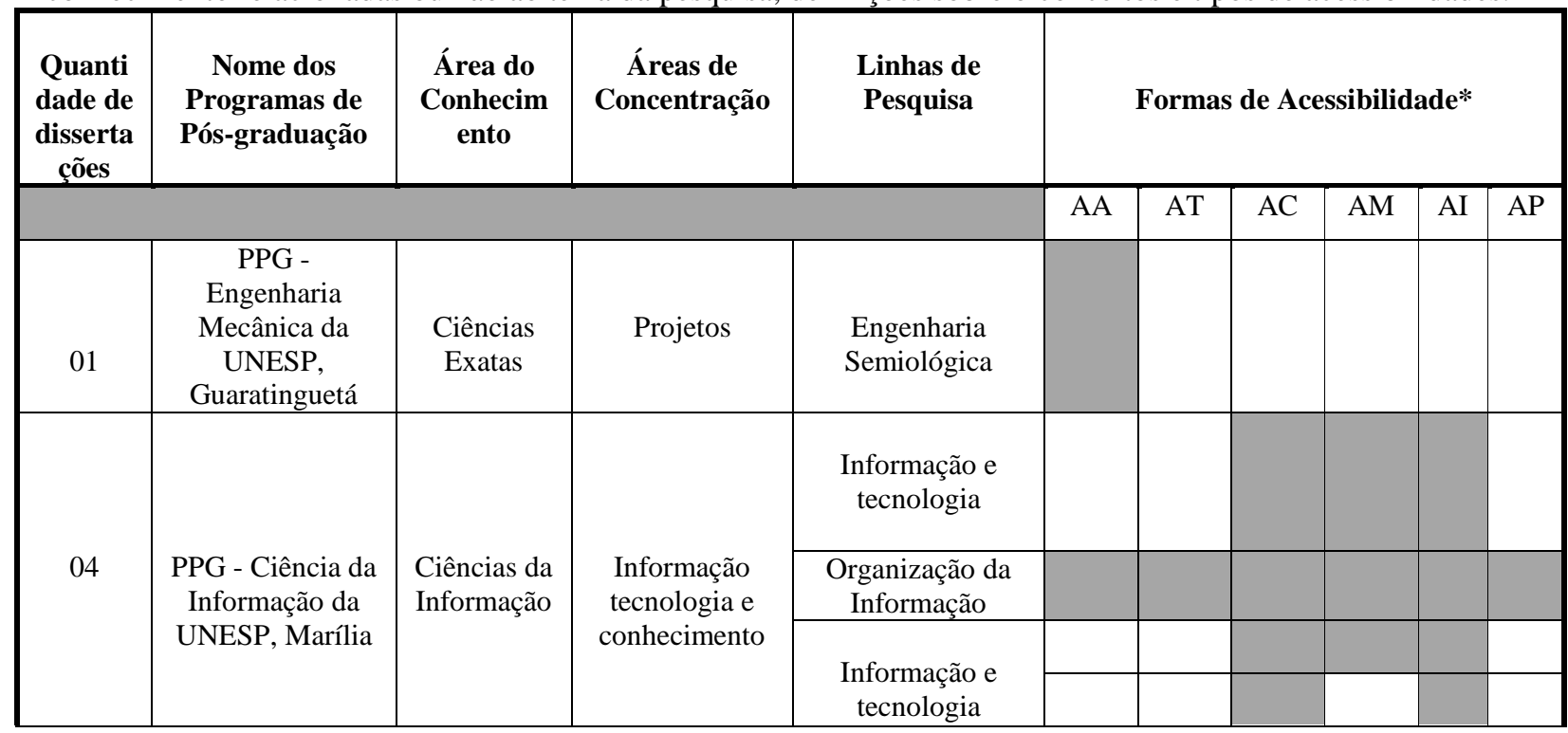




\begin{tabular}{|c|c|c|c|c|c|c|c|c|c|c|}
\hline \multirow[b]{2}{*}{02} & \multirow{2}{*}{$\begin{array}{l}\text { PPG - Televisão } \\
\text { digital: } \\
\text { informação e } \\
\text { conhecimento, } \\
\text { UNESP, Bauru }\end{array}$} & \multirow[b]{2}{*}{$\begin{array}{l}\text { Ciências } \\
\text { Humanas }\end{array}$} & \multirow{2}{*}{$\begin{array}{l}\text { Comunicação, } \\
\text { informação e } \\
\text { educação em } \\
\text { televisão } \\
\text { digital }\end{array}$} & $\begin{array}{c}\text { Informação e } \\
\text { tecnologia }\end{array}$ & & & & & & \\
\hline & & & & $\begin{array}{c}\text { Educação } \\
\text { Assistida por } \\
\text { televisão digital }\end{array}$ & & & & & & \\
\hline 01 & $\begin{array}{c}\text { PPG - } \\
\text { Comunicação da } \\
\text { UNESP,_Bauru }\end{array}$ & $\begin{array}{l}\text { Ciências } \\
\text { Humanas }\end{array}$ & $\begin{array}{l}\text { Comunicação } \\
\text { Midiática }\end{array}$ & $\begin{array}{l}\text { Gestão e políticas } \\
\text { da informação e } \\
\text { da comunicação } \\
\text { midiática }\end{array}$ & & & & & & \\
\hline \multirow{4}{*}{04} & \multirow{4}{*}{$\begin{array}{l}\text { PPG - Desenho } \\
\text { Industrial da } \\
\text { UNESP, Bauru }\end{array}$} & \multirow{4}{*}{$\begin{array}{l}\text { Ciências } \\
\text { Sociais } \\
\text { Aplicadas }\end{array}$} & \multirow{4}{*}{$\begin{array}{l}\text { Desenho do } \\
\text { Produto }\end{array}$} & Ergonomia & & & & & & \\
\hline & & & & & & & & & & \\
\hline & & & & Planejamento do & & & & & & \\
\hline & & & & Produto & & & & & & \\
\hline \multirow{3}{*}{03} & \multirow{3}{*}{$\begin{array}{l}\text { PPG - Educação } \\
\text { pela UNESP, } \\
\text { Presidente } \\
\text { Prudente }\end{array}$} & \multirow{3}{*}{$\begin{array}{l}\text { Ciências } \\
\text { Humanas }\end{array}$} & \multirow{3}{*}{ Educação } & \multirow{3}{*}{$\begin{array}{l}\text { Práticas e } \\
\text { processos } \\
\text { formativos de } \\
\text { educação }\end{array}$} & & & & & & \\
\hline & & & & & & & & & & \\
\hline & & & & & & & & & & \\
\hline \multirow{3}{*}{04} & \multirow{3}{*}{$\begin{array}{l}\text { PPG - Educação } \\
\text { pela UNESP, } \\
\text { Marília }\end{array}$} & \multirow{3}{*}{$\begin{array}{l}\text { Ciências } \\
\text { Humanas }\end{array}$} & \multirow{3}{*}{$\begin{array}{l}\text { Educação: } \\
\text { Ensino na } \\
\text { Educação } \\
\text { Brasileira }\end{array}$} & \multirow{3}{*}{$\begin{array}{c}\text { Educação } \\
\text { Especial no Brasil }\end{array}$} & & & & & & \\
\hline & & & & & & & & & & \\
\hline & & & & & & & & & & \\
\hline \multirow[b]{2}{*}{02} & \multirow{2}{*}{$\begin{array}{l}\text { PPG - Geografia } \\
\text { da UNESP, Rio } \\
\text { Claro. }\end{array}$} & \multirow[b]{2}{*}{$\begin{array}{l}\text { Ciências } \\
\text { Humanas }\end{array}$} & \multirow{2}{*}{$\begin{array}{l}\text { Geografia: } \\
\text { Organização } \\
\text { do Espaço }\end{array}$} & $\begin{array}{c}\text { Análise } \\
\text { Ambiental }\end{array}$ & & & & & & \\
\hline & & & & $\begin{array}{c}\text { Dinâmicas, } \\
\text { processos e } \\
\text { desenvolvimento } \\
\text { urbano e regional }\end{array}$ & & & & & & \\
\hline 01 & $\begin{array}{c}\text { PPG - Geografia } \\
\text { da UNESP, } \\
\text { Presidente } \\
\text { Prudente } \\
\end{array}$ & $\begin{array}{l}\text { Ciências } \\
\text { Humanas }\end{array}$ & $\begin{array}{l}\text { Desenvolvime } \\
\text { nto Regional }\end{array}$ & $\begin{array}{l}\text { Desenvolvimento } \\
\text { territorial }\end{array}$ & & & & & & \\
\hline \multirow[t]{2}{*}{02} & \multirow{2}{*}{$\begin{array}{l}\text { PPG - Geografia } \\
\text { da UNESP } \\
\text { Presidente } \\
\text { Prudente }\end{array}$} & \multirow{2}{*}{$\begin{array}{l}\text { Ciências } \\
\text { Humanas }\end{array}$} & \multirow{2}{*}{$\begin{array}{l}\text { Geografia: } \\
\text { Produção do } \\
\text { espaço } \\
\text { geográfico }\end{array}$} & \multirow[t]{2}{*}{$\begin{array}{l}\text { Produção do } \\
\text { Espaço Urbano }\end{array}$} & & & & & & \\
\hline & & & & & & & & & & \\
\hline \multirow[b]{2}{*}{02} & \multirow[b]{2}{*}{$\begin{array}{l}\text { PPG - Saúde } \\
\text { Coletiva pela } \\
\text { UNESP, } \\
\text { Botucatu }\end{array}$} & \multirow[b]{2}{*}{$\begin{array}{l}\text { Ciências da } \\
\text { Saúde }\end{array}$} & \multirow[b]{2}{*}{ Saúde Pública } & $\begin{array}{ll}\text { Condições } & \text { de } \\
\text { vida e saúde } & \text { de } \\
\text { populações } & \\
\end{array}$ & & & & & & \\
\hline & & & & $\begin{array}{lr}\text { Políticas } & \text { e } \\
\text { Práticas } & \text { de } \\
\text { Saúde: } & \text { Estudos } \\
\text { sobre } & \text { Gestão, } \\
\text { Planejamento } & \text { e } \\
\begin{array}{l}\text { Avaliação } \\
\text { Tecnologias, }\end{array} \\
\begin{array}{l}\text { Programas } \\
\text { Sistemas } \\
\text { Saúde }\end{array} \\
\end{array}$ & & & & & & \\
\hline \multirow{2}{*}{02} & $\begin{array}{c}\text { PPG - Psicologia } \\
\text { do } \\
\text { desenvolvimento }\end{array}$ & Ciências & $\begin{array}{l}\text { Psicologia do } \\
\text { Desenvolvime }\end{array}$ & & & & & & & \\
\hline & $\begin{array}{c}\text { e aprendizagem } \\
\text { pela UNESP, } \\
\text { Bauru } \\
\end{array}$ & $\begin{array}{l}\text { Cenclas } \\
\text { Humanas }\end{array}$ & $\begin{array}{l}\text { nto e da } \\
\text { Aprendizagem }\end{array}$ & $\begin{array}{l}\text { Aprendizagem e } \\
\text { Ensino }\end{array}$ & & & & & & \\
\hline 28 & & & & & 18 & 03 & 09 & 14 & 16 & 05 \\
\hline
\end{tabular}

Fonte: Elaborada pelos autores. 
*AA= acessibilidade arquitetônica (física); $\mathrm{AT}=$ acessibilidade atitudinal; $\mathrm{AC}=$ acessibilidade comunicacional; $\mathrm{AM}=$ acessibilidade metodológica; $\mathrm{AI}=$ acessibilidade instrumental; $\mathrm{AP}=$ acessibilidade programática.

No que se refere à acessibilidade arquitetônica, percebeu-se, de forma semelhante ao que foi encontrado na análise das teses, uma predominância de produções nessa dimensão, pois, do total de 28, nela foram identificadas 18 dissertações. Grande parte se concentrou na área de Ciências Humanas, na qual quatro dissertações pertenciam a programas de Geografia, sendo duas da área de concentração Produção do Espaço, linha de pesquisa Produção do Espaço Urbano. Uma delas estudou elementos concretos, que, de modo combinado, atuaram na geração de profundas desigualdades de acesso à cidade, prejudicando as várias categorias de interações espaciais e, por conseguinte, a própria cidade. Por sua vez, a segunda voltou-se para a compreensão de cidades brasileiras, onde o automóvel possui maior prioridade que o transporte público coletivo, assinalando problemas comuns relativos à mobilidade dos passageiros, os quais acarretam em dificuldades de acesso aos destinos desejados.

Foram detectadas ainda outras duas pesquisas pertencentes à área de Ciências Humanas, área de concentração Organização do espaço; a primeira, na linha de pesquisa Análise Ambiental, examinou as centralidades criadas com a expansão territorial urbana, verificando a maneira como dificultam a mobilidade e a acessibilidade das pessoas residentes em áreas de exclusão social, em comparação ao restante da cidade. A segunda se inseria na linha de pesquisa Dinâmicas, Processos e Desenvolvimento Urbano e Regional, constatando a circunstância de as barreiras impostas pela desigualdade social estarem sendo reduzidas por uma política de transporte público capaz de promover a mobilidade das pessoas e a sua acessibilidade aos locais de interesse; nesse sentido, a investigação enfocou a infraestrutura de mobilidade na cidade e a distribuição dos fluxos, em seu tecido urbano, como também as políticas públicas adotadas nesse cenário.

Além disso, identificou-se outro trabalho ligado à área de conhecimento Ciências Exatas, área de concentração Projetos e linha de pesquisa Engenharia Semiológica, que possibilitou conceber, projetar e dimensionar uma plataforma de acessibilidade, enfatizando o tipo plano inclinado para pessoas portadoras de deficiência e/ou usuários de cadeira de rodas.

Havia ainda quatro pesquisas vinculadas à área de conhecimento Ciências Sociais Aplicadas, duas delas pertencentes à área de concentração Desenho do produto, na linha pesquisa Ergonomia. Dessas, uma procurou compreender os espaços públicos urbanos, as condições de acessibilidade em seus espaços físicos, buscando identificar as principais dificuldades atinentes à situação das pessoas portadoras de deficiência física. A segunda, por sua vez, reuniu informações sobre os problemas da obesidade e sua relação com a 
acessibilidade e usabilidade de produtos, procurando apresentar e discutir as questões de interface entre usuários obesos e os produtos médico-hospitalares. As outras duas pesquisas pertencem à área de concentração Desenho do produto, na linha de pesquisa Planejamento do Produto, uma delas visou coletar informações sobre as reais necessidades dos portadores de deficiência física, que fazem uso da cadeira de rodas, frente aos produtos de moda que o mercado lhes oferece. Outra investigou formas para o desenvolvimento de pisos intertravados para pavimentação de áreas e passeios públicos. Realizaram-se análises históricas sobre o estado atual das calçadas, considerando a influência de fatores sociais, bem como as condições físicas e materiais do sistema dos passeios urbanos.

$\mathrm{Na}$ dimensão da acessibilidade atitudinal, encontraram-se três dissertações, duas da área das Ciências Humanas, área de concentração Psicologia do Desenvolvimento e da Aprendizagem, linha de pesquisa Aprendizagem e Ensino. Uma delas questionava se o ensino sobre acessibilidade, em cursos de Arquitetura, constitui atualmente uma ferramenta de inclusão social das pessoas com deficiência. A outra enfatizou as dificuldades, os mitos e os preconceitos enfrentados pelas pessoas com deficiência, ao ingressarem no mercado formal de trabalho, demonstrando as barreiras sociais, ambientais e atitudinais que dificultam a inclusão da pessoa com deficiência, consequentemente, discutindo normativas legais, diversidade e acessibilidade da pessoa com deficiência, assinalando sua grande importância no contexto laboral. Finalmente, uma dissertação da área do conhecimento Ciência da Informação, área de concentração Informação, tecnologia e conhecimento, linha de pesquisa Organização da informação buscou compreender a produção do conhecimento dos comportamentos informacionais realizados por docentes e discentes pesquisadores da Pós-Graduação, focalizando as necessidades informacionais de pós-graduandos surdos, de forma a estudar os sinalizadores que utilizam a língua brasileira de sinais. Vale ressaltar que os estudos elucidaram, além da acessibilidade atitudinal, todas as demais dimensões propostas por Sassaki (2003).

Na dimensão acessibilidade comunicacional, identificaram-se nove estudos, sendo que três já foram abordados na acessibilidade atitudinal e, portanto, não serão repetidos. Dos seis restantes, dois deles são ligados à área do conhecimento Ciências Humanas, área de concentração Educação Ensino na Educação brasileira, linha de pesquisa Educação Especial no Brasil. Um deles descreveu e analisou o ponto de vista do estudante com deficiência, com vistas às condições de acessibilidade na Universidade Estadual de Londrina (UEL), ao passo que a outra observou caminhos isotrópicos usados por cursistas com deficiência visual, na 
educação à distância, procurando verificar as condições de acessibilidade no ambiente virtual de aprendizagem (TelEduc) para a realização do curso de Tecnologia Assistiva.

Outros três estudos encontrados são voltados para a área do conhecimento Ciência da informação, área de concentração Informação, tecnologia e conhecimento, ambos da linha de pesquisa informação e tecnologia. O primeiro deles identificou e conceituou o campo da Ciência da Informação, no âmbito das tecnologias de informação e comunicação, e de que forma a área tem contribuído para o desenvolvimento de interfaces acessíveis, enquanto o segundo se debruçou sobre uma dual necessidade, tanto na arquitetura dos ambientes informacionais digitais, para uma maior usabilidade e acessibilidade, quanto no aperfeiçoamento dos repositórios digitais, de sorte a garantir a recuperação das informações preservadas para o uso e reuso. O terceiro ressaltou elementos que viabilizam a inclusão digital e social dos idosos, a partir dos estudos em Arquitetura da Informação, Usabilidade, Acessibilidade e Comportamento Informacional, no contex to da Ciência da Informação, assim como a aplicação desses elementos em um repositório digital construído para a Universidade Aberta à Terceira Idade (UNATI/UNESP).

No que tange à acessibilidade metodológica e instrumental, 14 dissertações se referiram ao conceito de acessibilidade metodológica, enquanto 16 conceituaram acessibilidade instrumental. Do total, 11 incluíram outras dimensões de acessibilidade, como acessibilidade arquitetônica, atitudinal, comunicacional e programática.

Uma delas, pertencente à área do conhecimento Ciências Humanas, área de concentração Comunicação, informação e educação na televisão digital, linha de pesquisa Informação e tecnologia, considerou as narrativas audiovisuais $\mathrm{e}$ interativas, $\mathrm{o}$ desenvolvimento de conteúdos e formatos, a eficácia da comunicação, na perspectiva da inclusão digital, como o design de aplicativos interativos capazes de promover acessibilidade e usabilidade do público com o conteúdo formatado para a TV digital e multiplataforma.

Cinco dissertações ligavam-se à área do conhecimento Ciências Humanas, sendo que três à área de concentração Educação: Ensino na Educação Brasileira, linha de pesquisa, Educação Especial. A primeira delas discutiu questões relacionadas à tecnologia assistiva, incluindo brinquedos e roupas adaptadas, computadores, softwares e hardwares especiais, os quais contemplam questões de acessibilidade; a segunda caracterizou a tecnologia assistiva como uma área do conhecimento, de característica interdisciplinar, que engloba produtos, recursos, metodologias, estratégias, práticas e serviços que objetivam promover a funcionalidade relacionada à atividade e participação de pessoas com deficiência; a terceira preocupou-se em elaborar um protocolo para avaliar as condições de acessibilidade física nas 
escolas de Educação Infantil, visando ao aspecto de locomoção dos alunos com deficiência. Já os outros dois trabalhos se inserem na área de concentração Educação, linha de pesquisa Práticas e Processos Formativos na Educação. A primeira se propôs descrever e analisar características de acessibilidade que devem ser encontradas nos Objetos Educacionais (OEs), nos conceitos de Física, disponibilizados no repositório do Banco Internacional de Objetos Educacionais (BIOE) para pessoas com Deficiência Visual (PDVs); a segunda abordou manifestações de educadores participantes do curso de aperfeiçoamento em "Tecnologia assistiva, projetos e acessibilidade: promovendo a inclusão", concernentes a compreensões e posturas correlatas à inclusão escolar de pessoas com deficiência, na rede municipal de ensino de Presidente Prudente, no interior paulista.

Na sequência, analisou-se uma dissertação na área do conhecimento Ciências Sociais Aplicadas, área de concentração Desenho do Produto, linha de pesquisa Ergonomia, a qual que reuniu informações sobre os problemas da obesidade e sua relação com a acessibilidade e usabilidade de produtos, procurando apresentar e discutir questões de interface entre usuários obesos e os produtos médico-hospitalares.

Por fim, tem-se a dimensão da acessibilidade programática, totalizando cinco pesquisas, duas das quais já foram discutidas no decorrer da análise, uma vez que se incluíam na dimensão comunicacional, metodológica e instrumental. Das demais, uma se inscrevia na área de Ciências Humanas, área de concentração Desenvolvimento Regional, linha de pesquisa Desenvolvimento Territorial, verificando a precarização territorial implementada na produção do espaço urbano acentuado pela exclusão social, no município de Marília. Esse trabalho indicou que as centralidades criadas com a expansão territorial urbana dificultavam a mobilidade e acessibilidade das pessoas residentes em áreas de exclusão social, em face do restante da cidade. Outros dois estudos foram desenvolvidos na área do conhecimento Ciência da Saúde, área de concentração Saúde Pública. O primeiro, relacionado à linha de pesquisa Condições de vida e saúde de populações, enfocou as condições de acesso dos usurários aos serviços da saúde. O segundo, inserido na linha de pesquisa Políticas e práticas de saúde: Estudos sobre gestão, planejamento e avaliação de tecnologias de programas e sistemas de saúde, retratou o emprego de serviços de saúde, avaliando de que maneira estes podem contribuir com a racionalização dos gastos, do planejamento, da reorganização das ações e programas, buscando melhorar a qualidade dos serviços prestados. Por fim, a terceira investigação reuniu informações que contextualizam teórica e conjunturalmente acessibilidade à rede pública de atenção básica à saúde de Botucatu. 


\section{Conclusão}

Este estudo procurou descrever os resultados obtidos na busca e análise do conceito de acessibilidade utilizado em dissertações e teses disponibilizadas na Biblioteca Digital de Teses e Dissertações da UNESP, classificando-os nas suas seis dimensões. Isso parece ser importante, face às políticas públicas de acessibilidade destinadas às pessoas com deficiência, atualmente estabelecidas, para a participação desse segmento populacional nas mais diversas esferas sociais. Com efeito, observar como a comunidade científica tem discutido essa temática é interessante, na medida em que isso revela como as pesquisas retratam as condições favoráveis e desfavoráveis de acessibilidade, nas suas dimensões física, atitudinal, instrumental, comunicacional e/ou metodológica, encontradas pelas pessoas com deficiência.

O total investigado consistiu em 38 trabalhos, sendo 28 dissertações e dez teses. Em geral, o conceito de acessibilidade nas teses enfatizava a dimensão física, seguida de destaque para as dimensões comunicacional, metodológica, instrumental e programática. No que se refere às dissertações, mais da metade das produções versava sobre o conceito na dimensão da acessibilidade física, paralelamente a algumas pesquisas que procuraram abordar sua dimensão metodológica e/ou instrumental. Poucos trabalhos trataram da dimensão acessibilidade atitudinal. Após a realização do estudo, percebeu-se que a temática acessibilidade está relacionada em alguma medida às pessoas com deficiência e tem sido discutida pela comunidade acadêmica nos trabalhos de Pós-Graduação.

No tocante aos resultados apresentados, notou-se uma predominância de teses e/ou dissertações na área de Ciências Humanas, principalmente na área específica da Geografia, discutindo a presença ou a eliminação das barreiras físicas, consideradas como impeditivos de autonomia para o acesso e a circulação, em diferentes ambientes físicos, como escolas, empresas, residências, edifícios públicos, centros de convenção, espaços urbanos, locais de lazer e turismo, nos meios de transporte individual ou coletivo. Os trabalhos apontaram que as barreiras arquitetônicas são os maiores empecilhos para as pessoas com deficiência - que usam cadeiras de rodas, bengalas ou muletas para se locomoverem -, dificultando a sua inserção na sociedade. Ademais, constatou-se que tais produções caracterizam a acessibilidade atrelada à mobilidade com autonomia, fundamentada no conceito de desenho universal. Desse modo, ganha destaque a "arquitetura acessível" como possibilidade de todas as pessoas terem condições de ir e vir livremente.

Por outro lado, identificou-se uma predominância de estudos (uma tese e oito dissertações) que retratam a dimensão da acessibilidade comunicacional, produzidas na área da Comunicação, Informação e Educação em Televisão Digital. Nesses, foram discutidas 
formas de eliminação de barreiras na comunicação interpessoal (face a face, língua de sinais, linguagem corporal, linguagem gestual etc.), na comunicação escrita (jornal, revista, livro, carta, apostila etc., incluindo textos em braile, textos com letras ampliadas para quem tem baixa visão, notebook e outras tecnologias assistivas para comunicar) e na comunicação virtual. É interessante destacar trabalhos que debateram a implantação da audiodescrição, na televisão digital brasileira, como um dos importantes agentes na inclusão social, cultural e escolar - sobretudo de pessoas com deficiência visual.

Dos quatro trabalhos que problematizaram a acessibilidade atitudinal, evidencia-se a promoção de atitudes livres de preconceitos, estereótipos e discriminações, na efetivação de práticas reflexivas com foco na diversidade humana. Tidas como as mais difíceis de serem removidas, as barreiras atitudinais são permeadas pela esfera social, em que as relações humanas se centram nas restrições dos indivíduos e não em suas habilidades, intimamente associadas à subjetividade, aos aspectos de formação simbólica, veiculadas e enfatizadas no contexto cultural. Percebe-se, portanto, que as barreiras atitudinais podem ser consideradas como prejudiciais para toda a sociedade, visto que são contrárias à cidadania de um determinado indivíduo ou de segmento social vulnerável - como, por exemplo, o caso das pessoas com deficiência.

Pode-se concluir que há necessidade de serem realizadas outras pesquisas, capazes de retratar a acessibilidade nos seus diversos contextos, pois ainda existem atitudes negativas mantidas pela sociedade com respeito às pessoas com deficiências, de sorte que cabe à universidade a promoção constante de estudos que favoreçam o reconhecimento da diversidade humana, a fim de que sujeitos nessas condições tenham mais chances de sair da exclusão e da marginalização social. Enfim, grupos sociais vulneráveis merecem a atenção da academia, para que políticas públicas possam ser executadas e que a garantia de seus direitos seja efetivada. Romper com os paradigmas e preconceitos atribuídos a essa demanda populacional certamente pode se constituir num caminho promissor para a construção de uma sociedade inclusiva.

\section{ACADEMIC PRODUCTIONS ABOUT “ACCESSIBILITY” IN THE C@THEDRA PORTAL}

\footnotetext{
Abstract

Eliminating the accessibility barriers, which hinder or difficult the access to higher education, is a highlighted theme in the present. This research objectived to describe the concept "accessibility" on the Brazilian scientific production made on the last ten years. For that, it
} 
was done a scan at the C@thedra portal, an electronic site owned by Unesp, which becomes available the results of Master and Doctoral researches, defended at post-graduate programs of that institution. The survey allowed identifying 66 documents, in which there were 22 thesis and 44 dissertations. Of that amount of material, 38 of them were selected to the analysis -10 thesis and 28 dissertations. The results indicate the scientific productions dealt with architectonic, methodological, communicational and programmatic accessibility, followed by fewer works that referred to accessibility through an attitudinal and/or instrumental perspective to broaching the disability. Although such findings are still not very significant, if compared to the total of available academic productions in the electronic database, they show that the issue is gaining expression in the scientific community.

Keywords: Accessibility. Higher Education. Electronic Portals.

\title{
PRODUCCIONES EN "ACCESIBILIDAD" ACADÉMICO NO PORTAL C@THEDRA
}

\begin{abstract}
Resumen
La eliminación de las barreras de accesibilidad, lo que dificulta o difícil el acceso a la educación superior, es un tema destacado en el presente. Esto objetivos de investigación para describir el concepto de "accesibilidad" en la producción científica brasileña, hecho en los últimos diez años. Para ello, se realizó un análisis en el portal C@ Thedra un sitio electrónico propiedad de la Unesp, que se disponga de los resultados de Maestría y Doctorado investigado y defendido en los programas de posgrado de la institución. La encuesta permitió identificar 66 documentos, siendo 22 tesis y 44 disertaciones. Esta cantidad de material, 38 ellos fueron seleccionados para el análisis - 10 tesis y 28 disertaciones. Los resultados indican las producciones científicas tratadas accesibilidad arquitectónica, metodológico, comunicacional y programático, seguido por un menor número de obras que hacían referencia a la accesibilidad a través de una perspectiva actitudinal y/o instrumental para abordar la discapacidad. Aunque estos hallazgos aún no son muy significativas, si se compara con el total de producciones académicas disponibles en la base de datos electrónica, muestran que el tema tiene ganando expresión en la comunidad científica.
\end{abstract}

Palabras clave: Accesibilidad.Educación Superior. Portales electrónicos.

\section{Referências}

ASSOCIAÇÃO BRASILEIRA DE NORMAS TÉCNICAS. NBR 9050: acessibilidade de pessoas portadoras de deficiências a edificações, espaço, mobiliário e equipamentos urbanos. Rio de Janeiro: ABNT, 2004.

BRASIL. Lei $n^{o}$. 10.098, de 19 de dezembro de 2000. Estabelece normas gerais e critérios básicos para a promoção da acessibilidade das pessoas portadoras de deficiência ou com mobilidade reduzida, e dá outras providências. Brasília, DF, 2000.

Ministério da Educação. Decreto no ${ }^{\circ}$ 5.296/2004. Regulamenta as Leis $n^{\circ} 10.048$, de 08 de dezembro de 2000, que dá prioridade de atendimento às pessoas que especifica, e 10 . 098, de 19 de dezembro de 2000, que estabelece normas gerais e critérios básicos para a promoção de acessibilidade das pessoas portadoras de deficiência ou com mobilidade 
reduzida, e dá outras providências. Diário Oficial da União da República Federativa do Brasil. Brasília, DF, 3 de dezembro de 2004.

Ministério da Educação. Decreto no 6.949/2009. Brasília, ago. 2009. Promulga a Convenção Internacional sobre os Direitos das Pessoas com Deficiência e seu Protocolo Facultativo, assinados em Nova York, em 30 de março de 2007. Diário Oficial da União da República Federativa do Brasil. Brasília, DF, 25 de agosto de 2009.

Cartilha de Acessibilidade para Web. Fascículo I. Brasília, 2013. Disponível em: $<$ http://www.w3c.br/pub/Materiais/PublicacoesW3C/cartilha-w3cbr-acessibilidade-webfasciculo-I.htm> Acesso em: 09 dez. 2014.

CARDOSO, M. A. C. C. Barreiras arquitetônicas no ambiente construído. 1996. 205 f. Dissertação (Mestrado em Engenharia) - Escola de Engenharia de São Carlos, Universidade de São Paulo, São Carlos, 1996.

CONSELHO NACIONAL DO DESENVOLVIMENTO CIENTÍFICO TECNOLÓGICO. Classificação das áreas do conhecimento. Brasil, 2005. Disponível em: 〈www.cnpq.br> Acesso em: 03 dez. 2014.

FERREIRA, N. S. As pesquisas denominadas "estado da arte". Educação \& Sociedade, Campinas, ano 23, n. 79, p. 257-272, 2002. Disponível em: <http://www.fe.unicamp.br/alle/textos/NSAFAsPesquisasDenominadasEstadodaArte.pdf $>$. Acesso em: 04 dez. 2014.

MANZINI, E. J. Scientific journal evaluation: Brazilian Journal of Special Education. Rev. bras. educ. espec., Marília, v. 19, n. 1, p. 121-130, mar. 2013. Disponível em: $<\mathrm{http}: / / \mathrm{www}$.scielo.br/scielo.php?script=sci_arttext\&pid=S 141365382013000100009\&lng=pt \&nrm=iso> Acesso em: 02 dez. 2014.

MICHELS, L. R. F. A inclusão/exclusão da pessoa portadora de necessidades especiais no contexto universitário. 2000. 101f. Dissertação (Mestrado em Psicologia Social e de Personalidade) - Pontifícia Universidade Católica do Rio Grande do Sul, Porto Alegre, 2000.

SASSAKI, R. K. Inclusão no lazer e no turismo: em busca da qualidade de vida. São Paulo: Áurea, 2003.

Data de recebimento: 10/02/15

Data de aceite: $26 / 08 / 15$ 


\section{Sobre as autoras:}

Ana Paula Silva Cantarelli Branco é Mestre em Psicologia do Desenvolvimento e da Aprendizagem - Universidade Estadual Paulista - UNESP/Bauru. Endereço eletrônico: paulasc_psi@yahoo.com.br

Lucia Pereira Leite é Professora do Departamento de Psicologia e do Programa de Pósgraduação e, Psicologia do Desenvolvimento e Aprendizagem, Faculdade de Ciências, Universidade Estadual Paulista - UNESP/Bauru. Endereço eletrônico: lucialeite @ fc.unesp.br

Sandra Eli Sartoreto de Oliveira Martins é Professora do Departamento de Educação Especial e do Programa de Pós-Graduação em Educação, da Faculdade de Filosofia e Ciências, Universidade Estadual Paulista - UNESP/Marília. Endereço eletrônico: sandreli@marilia.unesp.br 